\title{
REMOVAL OF VOCS FROM GROUNDWATER USING MEMBRANE-ASSISTED SOLVENT EXTRACTION*
}

\section{Joseph C. Hutter, George F. Vandegrift, Luis Nunez,} and David H. Redfield

\section{Argonne National Laboratory Chemical Technology Division}

The submitted manuscript has been authored
by a contractor of the U.S. Government
under contract No. W.31-109ENG.38.
Accordingly, the U. S. Government retains a
nonexclusive, royalty-free license to publish
or reproduce the published form of this
contribution, or allow others to do so, for
U.S. Government purposes.

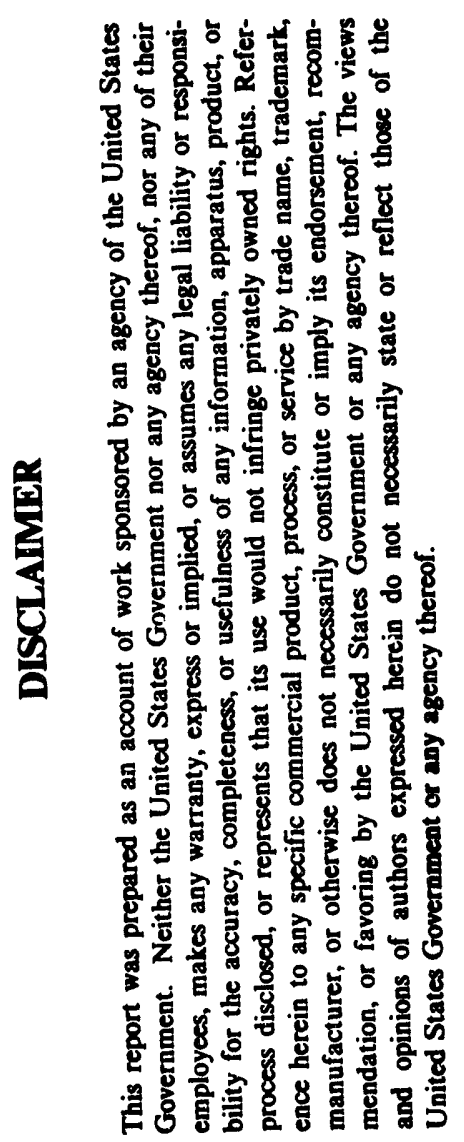

${ }^{\star}$ Work supported by the U. S. Department of Energy, Nuclear Energy Research and Development Program, under Contract W-31-109-Eng-38 


\title{
Removal of VOCs from Groundwater Using Membrane-Assisted Solvent Extraction
}

\author{
Joe C. Hutter, David H. Redfield, \\ Luis Nuñez, and George F. Vandegrift \\ Chemical Technology Division \\ Argonne National Laboratory \\ 9700 S. Cass Avenue \\ Argonne IL, 60439
}

\begin{abstract}
A membrane-assisted solvent extraction (MASX) system coupled to a membrane-assisted distillation stripping (MADS) system for use in decontaminating groundwater is discussed. Volatile organic compounds (VOCs) are extracted in the MASX using a sunflower oil solvent. In the MADS, VOCs are stripped from the sunflower oil, and the oil is recycled to the MASX. Thermodynamic data for the sunflower oit-water-VOCs system were experimentally collected. Published membrane-mass transfer results along with these data were used to design the MASX and MADS modules.
\end{abstract}

\section{Introduction}

Membrane-assisted solvent extraction is an emerging new technology in the chemical industry with many potential applications. Prasad and Sirkar IPRASAD and SIRKAR-1987, -1988, -1990] have demonstrated solvent extraction using this technology on several liquid-liquid systems. They have worked out the details for a resistance in series mass transfer model to evaluate the film resistances and membrane resistances for these types of systems. Yang and Cussler IYANG and CUSSLER-1986] evaluated and correlated the mass transfer resistances of the liquid films for these types of modules. Their work was primarily with mass transfer of oxygen from air into water; some work was also done on the mass transfer of carbon dioxide into water. These systems are well known liquid-phase-controlled mass transfer processes. Yang and Cussler evaluated a standard lab-scale shell-and-tube 
configuration module, and a pure cross-flow lab-scale module. Their dimensionless analysis results were consistent with astablished heat transfer results for analogous geometries.

Membrane-assisted solvent extraction has several advantages over conventional solvent extraction. The microporous membranes are used to separate the liquid phases, so that extraction can occur without the conventional mixing followed by phase separation. In the membrane extraction modules the two liquid phases are contacted with the interface immobilized by the microporous membrane. No phase separation is required because the two liquid phases are never mixed. This allows independent variation of the two liquid flow rates without the problems of flooding, stable emulsion formation, or poor contacting resulting in a low stage efficiency. The surface area per unit volume of contacting module is higher than in conventional packed or agitated columns, so that mass transfer is enhanced due to the larger interfacial area. The interfacial area in these modules can be accurately determined from the fiber dimensions and characteristics; thus the equipment is easily characterized for pilot plant tests and scale-up.

The high surface area enhances the mass transfer in these modules and makes them ideal candidates for applications of solvent extraction to dilute systems. Groundwater remediation and some process water applications require the recovery of dilute VOCs in the ppm-ppb range. Dilute concentrations of VOCs (ppb) are commonly found large distances from the Immediate contamination source, and recovery of these dilute VOCs from the aquifer is a very difficult remediation problem. The most widely used technology to remove dilute VOCs from water is air stripping [BROWN-1991]. Membrane extraction technology is effective in the same concentration range of VOCs as air stripping.

Zander and Semmens et al., first demonstrated this technology for recovering dilute VOCs from water using sunflower oil as the solvent [ZANDER-1989A, SEMMENS-1990]. They used a composite microporous polypropylene membrane coated with a disiloxane polymer in their studies. This unique design allowed the pores to remain gas filled, thus they claimed that the mass transfer resistance of the membrane was considerably reduced. Our work shows that oil-filled pores in a microporous membrane extraction gives a comparable overall resistance to the gasphase dense-phase composite membrane extraction used by Semmens. Thus, overall mass transfer coefficients are about the same in both extraction configurations. This results from the favorable equilibrium partitioning of the VOCs between the water and the oil phases. Zander demonstrated that the extraction of the VOCs worked; the 
regeneration of the solvent was much more difficult. A previous paper describes the MASX/MADS system and data needed to design one [HUTTER]. Since that time, we have collected the required thermodynamic data to evaluate this new membrane technology for both the extraction step and the regeneration of the solvent. A preliminary design of a pilot -scale membrane-assisted solvent extraction (MASX) system coupled to a membrane-assisted distillation stripping (MADS) system is discussed.

\section{Process Description}

The MASX/MADS system [HUTTER] consists of two types of hollow fiber units (Fig. 1). A nonvolatile organic solvent is used to extract the VOCs from the water in the MASX unit. In the MASX, the organic phase and aqueous phase flow countercurrently and are separated by the walls of membrane hollow fibers. The aqueous phase runs through the lumen; the solvent is on the shell side.

The VOC-contaminated water is contacted with the nonvolatile organic solvent and exits the MASX unit decontaminated of VOCs. The nonvolatile organic solvent containing the VOCs exits the MASX unit and is heated to $70^{\circ}-90^{\circ} \mathrm{C}$ then sent to the MADS unit to remove the VOCs from the nonvolatile solvent. In the MADS unit the nonvolatile organic solvent is stripped of VOCs by a gas phase. The VOCs, water which is extracted by the nonvolatile solvent, and a trace amount of solvent are vaporized into the stripping gas. The VOCs, water, and a trace amount of nonvolatile solvent is recovered from the stripping gas by a condenser. The stripping gas is recycled to the MADS to recover more VOCs from the nonvolatile solvent. The nonvolatile solvent is recycled to the MASX unit to recover more VOCs from the aqueous feed. Overall, this process has one feed, VOC contaminated water, and two products: decontaminated water and a concentrated solution of VOCs in water containing a trace amount of the nonvolatile solvent. A flow diagram of the process is shown in Fig. 1. 


\section{Experimental}

In order to design the MASX/MADS system, various fundamental experimental data about each VOC, water, and sunflower oil are needed. The experimental procedures used to obtain these data are discussed here.

Quantitative Analysis of VOCs. A Varian 3400 gas chromatograph equipped with photoionization and electrolytic conductivity detectors was used to measure VOC concentrations in water and sunflower-oil samples. A Tekmar LSC-2000 purge-andtrap concentrator was used to recover the VOCs from the samples. Water samples were evaluated using a method identical to EPA Method 502.2. Sunflower oil samples were heated to $90^{\circ} \mathrm{C}$ in a $5 \mathrm{~mL}$ fritless purge cell to recover the VOCs from the samples for adsorption onto the trap. The GC was equipped with a $30 \mathrm{~m} \times 0.53 \mathrm{~mm}$ ID Supelco VOCOL column with a $3 \mu \mathrm{m}$ film. Helium carrier gas was used at a flow rate of $6 \mathrm{mi} . / \mathrm{min}$. The $\mathrm{GC}$ oven was temperature programmed for $5^{\circ} \mathrm{C}$ for $35 \mathrm{~min}$, then ramped to $150^{\circ} \mathrm{C}$ at $10^{\circ} / \mathrm{min}$. Data were collected using a 2-channel Spectra-Physics Model SP4290 integrator and Winner386 software package.

Distribution Ratio Measurements. Equilibrium distribution ratios for each VOC between oil and water (D-values) were experimentally measured by contacting sunflower oil, water, and each VOC in a centrifuge tube submerged in a temperature-controlled bath. Samples were mixed, then separated in a centrifuge; the temperature was maintained by subsequent immersion in a controlled temperature bath before samples of both the aqueous and organic phases were analyzed for each VOCs concentration. Care was taken to avoid any head space in sample vials since VOCs were found to be rapidly lost from liquids exposed to an open headspace.

Henry's Law Constant Measurements. Henry's Law Constants were measured in a sparged gas reactor similar to the one used by MacKay [MACKAY-1979]. The reactor, which is shown in Fig. 2, is made out of glass and is $6.35 \mathrm{~cm} I D$ and $63.5 \mathrm{~cm}$ long. The reactor holds $1.70 \mathrm{~L}$ of liquid when full. This reactor is longer than the one used by MacKay. Nitrogen gas was sparged into the reactor by a sintered glass diffuser. The gas flowrate was measured by factory calibrated Cole-Palmer rotameter Model N112-02. Gas flows were varied from $0.5 \mathrm{~mL} / \mathrm{s}$ to $3.5 \mathrm{~mL} / \mathrm{s}$. Temperature was controlled by circulating water through a external heating jacket. The heat transfer water was circulated to a temperature controlled bath. The reactor temperature itself 
was monitored by a thermocouple. Samples of the liquid were withdrawn from the reactor using a syringe with an extended needle. A mixer (not shown) with three $2.54 \mathrm{~cm}$ marine impellers equally spaced on a $45 \mathrm{~cm}$ shaft was installed to improve the mixing of the high viscosity oil and insure a completely mixed liquid phase. The entire reactor was placed inside a fume hood.

The mass transfer of a sparingly soluble component in a liquid phase to gas phase is a liquid phase controlled process. For a fine bubble diffuser system, it has been observed that fine bubbles rapidly approach equilibrium with a sparingly soluble substance in the liquid phase within the first $15 \mathrm{~cm}$ of the disengagement of the bubbles from the diffusers. This phenomena has been successfully applied to measure the Henry's Law Constants for various VOCs in water [MACKAY-1979]. The technique requires accurate concentration vs. time data for desorption of a VOC from a sparged reactor. A material balance on the reactor allows one to calculate the Henry's Law Constant from the concentration vs. time data.

The material balance must include subsurface mass transfer between the dispersed gas and the bulk liquid as well as mass transfer at the liquid surface in contact with an infinite sink of gas [MCWHIRTER and HUTTER-1989]. The Henry's Law Constant is determined from the portion of the mass transfer due to the subsurface effects. The subsurface gas dispersion exits the reactor in equilibrium with the completely mixed liquid phase. A material balance for each VOC component is given by Eq. 1 .

$$
V_{L} \frac{d C_{o i}}{d t}=-G \frac{H_{i} R T C_{o i}}{P}-K_{L S} a_{S}\left(C_{o i}-C_{o i}{ }^{*}\right)
$$

Because the reactor was installed in a fume hood which is continuously purged with clean air, as the sparge gas exits the reactor, it is rapidly entrained by the large fume hood gas flow. Due to the high volumetric flow of the fume hood gas, the gas above the reactors turbulent liquid surface does not contain any VOCs, and $\mathrm{C}_{\mathrm{oi}}{ }^{*}$ is zero. Equation 1 can be integrated with the initial condition, $\mathrm{C}_{\mathrm{oi}}=\mathrm{C}_{\mathrm{oi}}{ }^{\circ}$ at $\mathrm{t}=0$.

$$
\ln \frac{C_{o i}}{C_{o i}^{o}}=-\left(\frac{G H_{i} R T}{P}+K_{L S} a_{S}\right) \frac{t}{V_{L}}
$$

The sparged reactor was initially filled with a $1000 \mathrm{ppb}$ of each of the VOCs listed in Table 1. Grab samples were taken from the reactor, and the concentration vs. time 
results were collected for each VOC. Experiments in the sparged reactor were evaluated using Eq. 2. From the zero gas rate test, $\mathrm{G}=0$ in Eq. $2, \mathrm{~K}_{\mathrm{LS}} \mathrm{a}_{\mathrm{S}}$ could be determined. This value of $K_{L S} a_{S}$ was used in the experiments with the gas flow in the calculation of the Henry's Law Constants using Eq. 2. A plot of typical experimental data is shown in Fig. 3. As predicted by Eq. 2, a plot of $\ln \mathrm{C}_{\mathrm{oi}} / \mathrm{C}_{\mathrm{oi}}{ }^{\circ} \mathrm{vs}$. $\mathrm{t}$ is a straight line. The least squares fit of the slope was used in the analysis.

The zero gas flow rate line shown in Fig. 3 is for the component methylene chloride. Since all the components were desorbed at almost the same rate, the zero gas rate values of $\mathrm{K}_{\mathrm{LS}} \mathrm{a}_{\mathrm{S}}$ were all within about $10 \%$ of each other for all the components. This would be expected since all the components have about the same diffusivity in the sunflower oil, and the mass transfer coefficient is directly proportional to the diffusivity according to the standard theoretical arguments of the film theory [BIRD-1960]. Methylene chloride had the highest estimated diffusivity in sunflower oil and thus it showed the most rapid loss from the sparged reactor in the zero gas tests.

Viscosity Measurement. The viscosity of sunflower oil was measured using a Brookfield Viscometer Model LVF. The liquid was contained in a temperature controlled cylindrical test cell. A cylindrical spindle was used on the viscometer.

Water Solubility Measurements. The water concentration in sunflower oil in equilibrium with pure water at $20^{\circ} \mathrm{C}$ was measured using a Karl Fischer Coulometer, Model KF652. The coulometer was calibrated with hydranal standard methanol (Riedel-de Haen AG, Switzerland) which contained $5.00+/-0.02 \mathrm{mg}$ water $/ \mathrm{mL}$. Sample sizes of $5-25 \mu \mathrm{L}$ of sunflower oil equilibrated with water were introduced into the Karl Fisher Coulometer titration system.

Reagent Chemicals. The analytical reagent quality VOCs used in this study were purchased from Aldrich Chemical Co., Milwaukee WI, and Fisher Scientific Co., Pittsburgh PA. Sunflower oil was a commercial edible grade manufactured by HuntWesson, Inc., Fullerton CA that was purchased locally. Water was obtained from the laboratory deionized and distilled water system. In addition, all the water was heated to $70^{\circ} \mathrm{C}$, and sparged with nitrogen for at least $4 \mathrm{hr}$ prior to use. This procedure insured that no VOCs could be detected in the water using our analytical equipment. 


\section{Measured Thermodynamic and Physical Properties}

The important properties required to design the MADS/MASX are reported below.

Distribution Ratios. The partitioning of the VOCs between the feed water and the nonvolatile solvent is an important parameter in designing the MASX unit. D-values between water and sunflower oil at $20^{\circ} \mathrm{C}$ are shown in Table 1. As shown in the table, VOCs that can hydrogen bond with water (e.g., chloroform) have consistently smaller D-values then those components which do not hydrogen bond, (e.g., carbon tetrachloride). Components such as carbon tetrachloride, or weakily hydrogen bonding components such as trichloroethylene, tend to break-up the hydrogen bonding structure in water and thus are energetically favored to partition to the oil phase. This effect is also observed in a homologous series of alcohols, i.e., decreasing solubilties in water as chain lenght increases (methanol is miscible with water, $n$-butanol is not). Intermediate $D$-value components such as benzene do not hydrogen bond with water, but can interact with water by induced polarization effects, which tend to lower the D-values compared to the components like carbon tetrachloride [KING-1982, -1984].

Table 1. D-values for 8 Candidate VOCs between Water and Sunflower Oil at $20^{\circ} \mathrm{C}$

\begin{tabular}{lc}
\hline Component & $\mathrm{D}=\frac{\mathrm{C}_{\mathrm{oi}}}{\mathrm{C}_{\mathrm{i}}}$ \\
\hline Methylene Chloride & 47 \\
Trans-1,2-Dichloroethylene & 130 \\
Cis-1,2-Dichloroethylene & 120 \\
Chloroform & 91 \\
1,1,1-Trichloroethane & 340 \\
Carbon Tetrachloride & 770 \\
Benzene & 210 \\
Trichloroethylene & 340 \\
\hline
\end{tabular}


Henry's Law Constants in Sunflower Oil. The Henry's Law Constants for the VOCs in sunflower oil are summarized in Table 2. As shown in the table, the Henry's Law Constants in sunflower oil can be correlated with the pure component boiling points of each VOC. Components are in vapor-liquid equilibrium in a capillary column GC. Therefore, the retention time is directly related to the partial pressures of the components above the stationary phase. Also as shown in the table, the components are listed in the order that they elute from the GC.

Table 2. Pure Component Boiling Points and Henry's Law Constants in Sunflower Oil

\begin{tabular}{lccccc}
\hline Component & $\begin{array}{c}\text { Boiling Pt. } \\
{ }^{\circ} \mathrm{C}, 1 \mathrm{~atm}\end{array}$ & $\begin{array}{c}\text { Retention } \\
\text { Time, min }\end{array}$ & $50^{\circ} \mathrm{C}$ & $70^{\circ} \mathrm{C}$ & $90^{\circ} \mathrm{C}$ \\
\hline \multirow{2}{*}{ Methylene Chloride } & 40.0 & 10.5 & 0.021 & 0.029 & 0.071 \\
Trans-1,2-Dichloroethylene & 47.0 & 12.0 & 0.018 & 0.025 & 0.071 \\
Cis-1,2-Dichloroethylene & 60.0 & 21.9 & 0.012 & 0.020 & 0.036 \\
Chloroform & 61.7 & 24.0 & 0.0099 & 0.015 & 0.037 \\
1,1,1-Trichloroethane & 74.1 & 28.8 & 0.010 & 0.015 & 0.034 \\
Carbon Tetrachloride & 76.6 & 32.0 & 0.0099 & 0.017 & 0.031 \\
Benzene & 80.0 & 35.6 & 0.010 & 0.017 & 0.028 \\
Trichloroethylene & 87.0 & 39.1 & 0.0062 & 0.011 & 0.019 \\
\hline
\end{tabular}

The Henry's Law Constants can also be correlated by Eq. 3.

$$
\ln H_{i}=-\frac{\Delta H_{i \text { diss }}}{R T}+\frac{\Delta S_{i \text { diss }}}{R}
$$

Figure 4 shows a plot of In $H_{\mathrm{i}}$ vs. $1 / \mathrm{T}$ typical for the VOCs we studied. The thermodynamic quantities obtained from these plots are listed in Table 3. The values of $\Delta \mathrm{H}_{\mathrm{i} \text {,diss }}$ agree well with the published values of $\Delta \mathrm{H}_{\text {vap }}$ for the pure components at their boiling points [LIDE-1991]. As shown in the table, the pure component enthalpies are smaller than the enthalpies of dissolution from sunflower oil. This indicates that it takes more energy to vaporize the VOCs from the sunflower oil as compared to the pure c:omponents, thus indicating the high affinity of the sunflower oil for the VOCs. 
Using these data, it is possible to extrapolate our experimental Henry's Law constant data over a wide range of temperatures, which will be useful in optimizing the MADS unit.

Table 3. Thermodynamic Quantities of Various VOCs in Sunflower Oil

\begin{tabular}{lccc}
\hline Component & $\begin{array}{c}\Delta \mathrm{H}_{\mathrm{i}, \text { vap }} \\
(\mathrm{KJ} / \mathrm{moL})\end{array}$ & $\begin{array}{c}\Delta \mathrm{H}_{\mathrm{i} \text {,diss }} \\
(\mathrm{KJ} / \mathrm{moL})\end{array}$ & $\begin{array}{c}\Delta \mathrm{S}_{\mathrm{i} \text {, diss }} \\
(\mathrm{J} / \mathrm{mol}-\mathrm{K})\end{array}$ \\
\hline Methylene Chloride & 28.1 & 43 & 96 \\
Trans-1,2-Dichloroethylene & - & 42 & 94 \\
Cis-1,2-Dichloroethylene & - & 34 & 65 \\
Chloroform & 29.2 & 41. & 86 \\
1,1,1-Trichloroethane & 29.9 & 38 & 78 \\
Carbon Tetrachloride & 29.8 & 40 & 83 \\
Benzene & 30.8 & 39 & 79 \\
Trichloroethylene & 31.4 & 38 & 71 \\
\hline
\end{tabular}

Viscosity of Sunflower Oil. The viscosity measurement results are shown in Fig. 5. At all temperatures tested except $10^{\circ} \mathrm{C}$, the sunflower oil was Newtonian; its viscosity was independent of shear rate. Even at $10^{\circ} \mathrm{C}$, the sunflower oil was close to Newtonian. Viscosity was found to decrease with temperature as expected.

\section{MASX Unit Design}

Design Basis for the MASX/MADS. To evaluate the performance of the MASX/MADS process, an aqueous flow rate of $378.5 \mathrm{~L} / \mathrm{min}$ was chosen. The inlet concentration was set at $10 \mathrm{ppm}$, which is high compared to most groundwater remediation problems. The MASX was designed to remove VOCs to at least $10 \mathrm{ppb}$, the drinking water standard typical for common VOCs. This is a decontamination factor of 1000 , which is beyond the performance of most conventional remediation equipment. An O/A of 0.1 was chosen to conserve the sunfiower oil flow.

The mass transfer of the VOCs between the water and oil phases in a countercurrent flow shell-and-tube module can be modeled by the following equations. These equations assume that the mass transfer of the VOC components are independent of 
each other, there are no interaction effects. This assumption works best in dilute solutions, which is the case for the application being considered. For the water inside the fibers, the following equation applies.

$$
v \frac{d C_{i}}{d z}=-K_{L} a\left(C_{i}-C_{i}^{*}\right)
$$

Membranes are a unique system since the interfacial area for mass transfer can be calculated from the geometry of the membranes. For the case here, the water-oil interface is immobilized at the inside wall of the hollow fibers. Thus the area is based on the inside diameter of the fibers. The area per unit volume of fiber is simply $4 / \mathrm{d}_{1 D}$.

If the oil is assumed to enter the module clean, containing no VOCs, the following material balance will apply at any cross section in the module.

$$
C_{o i}=\frac{L}{V}\left(C_{i-i n}-C_{i}\right)
$$

By using the definition of a D-value, Eq. 5 can be rewritten as,

$$
C_{i}^{*}=\frac{L}{V D_{i}}\left(C_{i-i n}-C_{i}\right)
$$

Equation 6 can be substituted into $\mathrm{Eq}_{q} 4$ for $\mathrm{C}_{i}$, and integrated with the boundary condition $C_{i}=C_{i-\text { in }}$ at $z=0$.

$$
\frac{C_{i}}{C_{i-1 i}}=\frac{R_{i} \operatorname{ExP}\left(\frac{K_{L} a}{v} z \frac{\left(R_{i}-1\right)}{R_{i}}\right)-1}{R_{i}-1}
$$

Solution of Eq. 7 will give the concentration of $\mathrm{VOC}_{i}$ for any fiber length $z$ in a countercurrent shell and iube module, provided the overall mass transfer coefficient $K_{L}$ is known.

The overall mass transfer resistance can be considered the sum of three resistances in series: tube-side resistance, membrane resistance, and shell-side resistance. Yang and Cussler [YANG and CUSSLER-1986] developed a correlation to estimate $\mathrm{K}_{\mathrm{Lt}}$ from tube- and shell-side resistances. For the tube-side the following equation applies for the hollow fibers: 


$$
\frac{k_{L t} d_{I D}}{D_{A B}}=1.64\left(\frac{d_{I D}^{2} v}{D_{A B} z}\right)^{0.33}
$$

For the shell-side the following equation can be used to estimate the local masstransfer coefficient. This equation applies for fibers in a close-packed geometry, the situation in the shell-and-tube hollow fiber modules.

$$
\frac{k_{L s} d_{\theta}}{D_{A B}}=24
$$

The equivalent diameter is defined similarly to the hydraulic radius, four times the cross-sectional area divided [PERRY-1984]. The membrane resistance can be calculated by Eq. 10, developed by Prasad and Sirkar [PRASAD and SIRKAR-1988].

$$
k_{m}=\frac{D_{A B} \varepsilon_{m}}{\left(c\left(d_{\supset D}-d_{1 D}\right) / 2\right)}
$$

The resistances are additive, using Eq. 11 developed by Prasad and Sirkar [PRASAD and SIRKAR-1988] for a hydrophibic, microporous hollow fiber with water in the lumen and the oil phase in the shell.

$$
\begin{aligned}
& R_{\text {overall }}=R_{\text {tube }}+R_{\text {membrane }}+R_{\text {shell }} \\
& \frac{1}{K_{L} d_{I D}}=\frac{1}{k_{L t} d_{I D}}+\frac{1}{D_{i} k_{m} d_{L M}}+\frac{1}{D_{i} k_{L s} d_{O D}}
\end{aligned}
$$

The logarithmic mean diameter is calculated by Eq. 12 .

$$
d_{L M}=\frac{d_{O D}-d_{I D}}{\ln \frac{d_{O D}}{d_{I D}}}
$$

The diffusivities of each of the VOCs in water can be estimated by the Hayduk and Laudie modified equation of Wilke-Chang below. These data originally correlated 
dilute organic components in water, the system of interest on the tube-side in the MASX [PERRY-1984]. The diffusivities of several VOCs in water at $20^{\circ} \mathrm{C}$ are reported in Table 4.

$$
D_{A B}=7.4 \times 10^{-8} \frac{\left(2.26 M_{w}\right)^{0.5} T}{\mu_{W} V_{i}^{0.6}}
$$

The diffusivities of the VOCs in sunflower oil can be estimated from the water data using the dependences in the Stokes-Einstein Equation [PERRY-1984]. From this equation, the diffusivity is inversely proportion to the viscosity, thus the ratios of the viscosities of water to sunflower oil at $20^{\circ} \mathrm{C}$ can be used to estimate the diffusivities in sunflower oil. The diffusivities for sunflower oil are also shown in Table 4.

Table 4. Diffusivities of VOCs in Water.and Sunflower Oil at $20^{\circ} \mathrm{C}$

\begin{tabular}{lcc}
\hline Component & $\begin{array}{c}\text { Diffusivity } \\
\text { in Water } \\
\left(10^{-5} \mathrm{~cm}^{2} / \mathrm{s}\right)\end{array}$ & $\begin{array}{c}\text { Diffusivity in } \\
\text { Sunflower Oil } \\
\left(10^{-7} \mathrm{~cm}^{2} / \mathrm{s}\right)\end{array}$ \\
\hline Methylene Chloride & 1.14 & 1.90 \\
Trans-1,2-Dichloroethylene & 1.02 & 1.70 \\
Cis-1,2-Dichloroethylene & 1.03 & 1.72 \\
Chloroform & 0.99 & 1.65 \\
1,1,1-Trichloroethane & 0.88 & 1.45 \\
Carbon Tetrachloride & 0.89 & 1.49 \\
Benzene & 0.94 & 1.56 \\
Trichloroethylene & 0.93 & 1.55 \\
\hline
\end{tabular}

Using the results of Eqs. 8 through 12 and the appropriate physical property data, the mass transfer coefficients for a MASX can be estimated. The estimated mass transfer coefficients are shown in Table 5. As shown in the table, the smallest individual mass transfer coefficients result inside the membrane. Using the dependencies in Eq. 11, these membrane coefficients would be multiplied by the D-values in Table 1 (47-770). Even with including the D-values, the membrane resi_tance is the largest resistance and controls the overall mass transfer resistance. 
The $D$-values are also used to multiply the values of $\mathrm{K}_{\mathrm{Ls}}$ as shown in Eq. 11. Thus the shell-side oil resistance is the smallest contributor to the overall resistance. The tubeside resistance, although more important then the shell-side resistance, is typically about 10-100 times smaller than the membrane resistance. The overall mass transfer coefficients range from $0.4-4.6 \times 10^{-3} \mathrm{~cm} / \mathrm{s}$, which is about the same range as those found by Zander, et al., [ZANDER-1989A] at similar operating conditions.

A prototypical shell-and-tube configuration pilot scale membrane module would have the characteristics listed in Table 6 . The fibers in the module are made out of microporous polypropylene. This type of equipment is commercially available on a lab-scale and is under development on a pilot scale. The fiber characteristics are those of Hoechst Celanese X-10 hollow fibers, and they are marketed under the trade name Celgard. The Celgard fibers have been used in the work of Z Mar, et al. [ZANDER-1989A, -1989B], Sirkar, et al. [SIRKAR-1986], and Yang, et ai.,[YANG-1986], and others.

Table 5. Mass Transfer Coefficients in the MASX

\begin{tabular}{|c|c|c|c|c|}
\hline Components & $\begin{array}{l}\mathrm{K}_{\mathrm{Lt}} \\
\left(10^{-2} \mathrm{~cm} / \mathrm{s}\right)\end{array}$ & $\begin{array}{l}k_{m} \\
\left(10^{-6} \mathrm{~cm} / \mathrm{s}\right)\end{array}$ & $\begin{array}{l}\mathrm{K}_{\mathrm{Ls}} \\
\left(10^{-3} \mathrm{~cm} / \mathrm{s}\right)\end{array}$ & $\begin{array}{l}\mathrm{K}_{\mathrm{L}} \\
\left(10^{-3} \mathrm{~cm} / \mathrm{s}\right)\end{array}$ \\
\hline Methylene Chloride & 4.49 & 7.92 & 6.84 & 0.40 \\
\hline Trans-1,2-Dichloroethylene & 4.17 & 7.08 & 6.12 & 0.98 \\
\hline Cis-1,2-Dichloroethylene & 4.20 & 7.15 & 6.18 & 0.91 \\
\hline Chloroform & 4.10 & 6.91 & 5.97 & 0.67 \\
\hline 1,1,1-Trichloroethane & 3.76 & 6.08 & 5.25 & 2.11 \\
\hline Carbon Tetrachloride & 3.81 & 6.19 & 5.35 & 4.56 \\
\hline Benzene & 3.94 & 6.51 & 5.62 & 1.43 \\
\hline Trichloroethylene & 3.93 & 6.47 & 5.59 & 2.25 \\
\hline
\end{tabular}


Table 6. Membrane Module Characteristics

\begin{tabular}{ll}
\hline Module Diameter $(\mathrm{cm})$ & 20 \\
Void Fraction & 0.65 \\
Number Fibers & 110,000 \\
Fiber Length $(\mathrm{cm})$ & 100 \\
Fiber ID $(\mathrm{cm})$ & 0.034 \\
Fiber OD $(\mathrm{cm})$ & 0.04 \\
Fiber Porosity $(\%)$ & 30 \\
Pore Size $(\mu \mathrm{m})$ & 0.05 \\
Area/Volume $\left(\mathrm{cm}^{2} / \mathrm{cm}^{3}\right)$ & 37.4 \\
No. Fibers/Area $($ No./cm $)$ & 350 \\
Liquid Velocity in Fibers $(\mathrm{cm} / \mathrm{s})$ & $0-10$ \\
\hline
\end{tabular}

Using Eq. 8 through 12, and the membrane module characteristics in Table 5, the mass transfer coefficients for a $387.5 \mathrm{~L} / \mathrm{min}$ pilot scale MASX can be calculated. For this design, the water is pumped through the lumen. Oil flows in the shell at a flowrate of $38.75 \mathrm{~L} / \mathrm{min}$ so that the MASX operates at an O/A of 0.1 . The velocity of water in the fibers controls the capacity of each module. For a velocity of $5.25 \mathrm{~cm} / \mathrm{s}$ in the fibers, each module with the characteristics in table 5 will have an aqueous flow of $31.5 \mathrm{~L} / \mathrm{min}$. Thus, 12 modules in parallel will be required to handle the $378.5 \mathrm{~L} / \mathrm{min}$ feed. The calculated individual mass transfer coefficients and the overall mass transfer coefficient are listed in Table 6 . A tortuosity of 2.5 was used for this calculation.

The results of the design calculations are displayed in Figure 6. As shown, carbon tetrachloride is the easiest component to extract since it has the highest D-value $\left(770\right.$ at $\left.20^{\circ} \mathrm{C}\right)$ and the highest relative mass transfer coefficient. The VOC most difficult to extract is methylene chloride, it has the smallest $D$-value and the smallest relative mass transfer coefficient. The percentage removal of each VOC for $2 \mathrm{~m}$ of fiber length is given in Table 7. Also shown in the table are the overall values of $K_{L}$ a for each component. All of the components except methylene chloride are removed by more than $97 \%$ after only $2 \mathrm{~m}$ of fiber length. About $8 \mathrm{~m}$ of fiber length would be required to remove $97 \%$ of the methylene chloride. Increases in fiber length can be achieved by putting the modules with the characteristics in Table 5 in series.

The mass transfer coefficients were estimated from sparingly-soluble-gas absorption data, for gases such as oxygen. The dimensionless forms used to estimate 
the mass transfer coefficients should correlate well with similar characteristic systems, i.e., sparingly soluble substances with high D-values (or Henry's Law Constants). Sparingly soluble systems of gas such as nitrogen, oxygen, carbon dioxide and argon in water all have been experimentaly observed to have about the same mass transfer coefficient as the correlated results for oxygen [MCWHIRTER-1978]. For mass transfer of volatile organic compounds, the alpha factor, the ratio of the VOC mass transfer coefficient to the rnass transfer coefficient of oxygen has been reported in the range of 0.5-0.7 [ROBERTS-1984, SMITH-1979], even for components with high solubilities in water such as acetone or chloroform. For these conditions, the mass transfer coefficients are very close to the values reported by Zander et al. [ZANDER-1989] in their gas-filled microporous composite membrane extraction module (0.6-2.5 $\mathrm{X}$ $10^{-3} \mathrm{~cm} / \mathrm{s}$ ). Therefore, the alpha factor for extraction in this system approaches unity based on these data because the oxygen-water correlations agree so well with Zander's results. All the diffusivities are within $15 \%$ of each other, so it should be expected that the individual film mass transfer coefficients should all fall within about the same range. As seen in Table 6, the individual film coefficients for the tube-side, membrane, and shell-side all do fall within the same range. The overall coefficients, however, vary by more than an order of magnitude due to the variation in the D-values. If this were not the case, the mass transfer coefficient for methylene chloride should be similar to the mass transfer coefficient of carbon tetrachloride instead of an order of magnitude smaller, as predicted by Eq. 11 .

Table 7. Overall Mass Transfer Coefficients in the MASX, and the Percentage Removal for a $2 \mathrm{~m}$ Fiber

\begin{tabular}{lcc}
\hline Component & $\begin{array}{c}\mathrm{K}_{\mathrm{L}} \mathrm{a} \\
\left(\mathrm{HR}^{-1}\right)\end{array}$ & $\begin{array}{c}\% \text { Removal } \\
2 \mathrm{~m} \text { Fiber }\end{array}$ \\
\hline Methylene Chloride & 169.4 & 79.8 \\
Trans-1,2-Dichloroethylene & 412.9 & 98.4 \\
Cis-1,2-Dichloroethylene & 385.8 & 97.8 \\
Chloroform & 284.2 & 93.8 \\
1,1,1-Trichloroethane & 893.6 & $>99.9$ \\
Carbon Tetrachloride & 1931.3 & $>99.9$ \\
Benzene & 605.6 & 99.8 \\
Trichloroethylene & 952.9 & $>99.9$ \\
\hline
\end{tabular}




\section{MADS Unit Design}

The MADS unit is unique because it operates at a relatively high temperature $70-90^{\circ} \mathrm{C}$. If a MADS were coupled to the MASX previously described, and the MASX were made long enough so that the VOCs in the aqueous stream exited at a concentration near the drinking water standards (10 ppb for each component), a stream of oil at a flowrate of $37.85 \mathrm{~L} / \mathrm{min}$ with about $100 \mathrm{ppm}$ of each VOC would leave the MASX unit and need to be regenerated in the MADS unit. This assumes a concentration of $10 \mathrm{ppm}$ for all VOCs in the groundwater feed.

The mass transfer in the MADS unit can be modeled in the same way as the MASX unit. For the oil flowing through the fibers the following equation applies.

$$
v \frac{d C_{o i}}{d z}=-K_{L} a\left(C_{o i}-C_{o i}^{*}\right)
$$

As in the case of the MASX unit, the interfacial area can be calculated from the geometry of the membranes. In this case the oil gas interface is immobilized at the outside wall of the fibers so that the interfacial area per unit fiber volume is simply $4 / d_{O D}$

If the stripping gas is assumed to enter the module clean, containing no VOCs, the following material balance will apply at any cross section in the module.

$$
C_{g i}=\frac{V}{G}\left(C_{o i-i n}-C_{o i}\right)
$$

By using the definition of Henry's Law Constant, Eq. 15 can be rewritten as,

$$
C_{o i}^{*}=\frac{V}{G H_{i}}\left(C_{o i-i n}-C_{o i}\right)
$$

Equation 16 can be substituted into Eq. 14 for $C_{o i}{ }^{*}$ and integrated with the boundary condition $\mathrm{C}_{\mathrm{oi}}=\mathrm{C}_{\mathrm{o}-\text { in }}$ at $\mathrm{z}=0$. 


$$
\frac{C_{o i}}{C_{o i-i n}}=\frac{R_{i} \operatorname{EXP}\left(\frac{K_{L} a}{v} z \frac{\left(R_{i}-1\right)}{R_{i}}\right)-1}{R_{i}-1}
$$

$R_{i}$ is equal to $G_{i} / N$ in Eq. 17. Solution of Eq. 17 will give the concentration of VOC for any fiber length $z$ in a counter-current shell and tube module, providing the overall mass transfer coefficient $K_{L} a$ is known, just like the case for the MASX. Equation 17 is similar to the well known published equations to design an air stripping column [OKONIEWSKI-1992].

As with modeling the MASX, an estimate of the mass transfer coefficient is needed for the MADS unit. In the MADS, oil will be in the lumen and a strip gas will be in the shell. The strip gas pressure must exceed the oil pressure so that the oil is contained in the pores. The oil could also be contained th the pores by using a coated membrane fiber; however, this solid film would significantly Increase the resistance to mass transfer.

Since oil is in both the tube and the fiber pores, Eq. 11 does not apply. An alternative form of Eq. 11 for this situation derived by Prasad and Sirkar [PRASAD and SIRKAR-1988] is given below. If a composite membrane with a dense phase coated fiber is used, an additional term including the resistance of the dense phase would need to be included in Eq. 18.

$$
\frac{1}{K_{L} d_{O D}}=\frac{1}{k_{L I} d_{O D}}+\frac{1}{k_{m} d_{L M}}+\frac{H_{i}}{k_{L s} d_{O D}}
$$

The gas-phase mass transfer can be neglected since $H_{i}$ is a small number for the sunflower oil system as shown previously in Table 2. An estimate of both the tube side mass transfer coefficient and the membrane mass transfer coefficient was obtained for sunflower oil at $90^{\circ} \mathrm{C}$, then the overall mass transfer coefficient was calculated using Eq. 18.

The membrane resistance can be estimated using the diffusivity of the VOCs in sunflower oil and the membrane properties reported in Table 6 . The diffusivity of the VOCs in sunflower oil was adjusted for temperature using the Stokes-Einstein dependencies as shown by Eq. 13 . The viscosity of sunflower oil at both $20^{\circ} \mathrm{C}$ and $90^{\circ} \mathrm{C}$ as shown in Fig. 5 was used in this calculation. This procedure is discussed in the Chemical Engineer's Handbook for adjusting diffusivity for temperature [Perry-1984]; it is empirical and it is inadequate compared to experimental data. It was 
used since no data are currently available for the sunflower oil system at the conditions in the MADS. Once the diffusivity was estimated, Eq. 10 was used to calculate $\mathrm{k}_{\mathrm{m}}$, and the results are shown in Table 8 . Based on this diffusivity estimate, the values of $k_{m}$ are small, and thus the membrane resistance is the major factor in the overall mass transfer resistance.

There are no available correlations for the tube-side resistances for sunflower oil at $90^{\circ} \mathrm{C}$. As an estimate, the surface mass transfer coefficients from the zero gas rate experiments in the sparged reactor at $90^{\circ} \mathrm{C}$ were used. These numbers are shown in Table 8. The values of $\mathrm{k}_{\mathrm{Lt}}$ from this estimate ranged from $4.0 \times 10^{-4}$ to $1.0 \times 10^{-3} \mathrm{~cm} / \mathrm{s}$, about $1-2$ orders of magnitude larger than the estimated values of $k_{m}$ for oil at $90^{\circ} \mathrm{C}$ in the MADS membrane as well as the values of $\mathrm{k}_{\mathrm{Lt}}$ predicted for the water in the tube-side of the MASX (Table 5). Thus, the tube-side resistance in the MADS is small, and the overall mass transfer resistance is dominated by the iembrane resistance. The overall mass transfer coefficients in the MADS are jummarized in Table 8.

Table 8. Mass Transfer Coefficients in MADS

\begin{tabular}{lcccc}
\hline Component & $\begin{array}{l}\text { Diffusivity } \\
90^{\circ} \mathrm{C} \\
\left(10^{-6} \mathrm{~cm}^{2} / \mathrm{s}\right)\end{array}$ & $\begin{array}{l}\mathrm{k}_{\mathrm{Lt}} \\
\left(10^{-4} \mathrm{~cm} / \mathrm{s}\right)\end{array}$ & $\begin{array}{l}\mathrm{k}_{\mathrm{m}} \\
\left(10^{-5} \mathrm{~cm} / \mathrm{s}\right)\end{array}$ & $\begin{array}{l}\mathrm{K}_{\mathrm{L}} \\
\left(10^{-5} \mathrm{~cm} / \mathrm{s}\right)\end{array}$ \\
\hline Methylene Chloride & 1.53 & 9.61 & 6.11 & 5.32 \\
Tra:IS-1,2-Dichloroethylene & 1.37 & 11.9 & 5.46 & 4.84 \\
Cis-1,2-Dichloroethylene & 1.38 & 6.47 & 5.52 & 4.72 \\
Chloroform & 1.33 & 6.89 & 5.33 & 4.59 \\
1,1,1-Trichloroethane & 1.17 & 5.70 & 4.69 & 4.02 \\
Carbon Tetrachloride & 1.19 & 6.27 & 4.78 & 4.12 \\
Benzene & 1.25 & 4.69 & 5.02 & 4.22 \\
Trichloroethylene & 1.25 & 4.70 & 4.99 & 4.20 \\
\hline
\end{tabular}

The overall mass transfer coefficients in the MADS are predicted in the range of 4.0-5.5 $\times 10^{-3} \mathrm{~S}^{-1}$. These estimates will have to be verified in a pilot study. The results of the design calculations for the MADS are shown in Fig. 7, the stripping gas flow was chosen to be $50 \mathrm{~L} / \mathrm{min}$ for these calculations. 
As shown in the figure, methylene chloride is the easiest component to strip, this should be no surprise since it was the most difficult to extract. 1,1,1-Trichloroethane is the most difficult component to strip since it has the smallest mass transfer coefficient due its small diffusivity. Methylene chloride has the largest diffusivity. All the other VOCs are intermediate between these two cases and are not shown on the figure. The VOC components were removed from the oil at rates directly proportional to their diffusivities. A MADS about $10-11 \mathrm{~m}$ fiber length is adequate to reduce the VOCs concentration in the oil phase by a factor of 10 . Another factor of 10 would require the same length of fiber. Fiber length could be increased by putting modules in series or parallel. A parallel configuration would be effective at increasing the fiber length until the flow rate though the fiber would be cut to the point that it increased tube side resistance. In order for the oil to be recycled to the MASX unit, it must be decontaminated to a level good enough so tilat the MASX unit meets its performance requirements. The oil fed back to the MASX must be low enough in VOCs so that groundwater does not stiip VOCs from the oil and make the aqueous contamination worse. The oil purity criteria is easily calculated using the extraction factor and the minimum length of the MADS fiber can be calculated once this target concentration is known. For MASX concentrations of groundwater approaching $10 \mathrm{ppb}$, the minimum purity of the oil and the length of the required fiber is listed in Table 9.

Table 9. Minimum Oil Purity Required for Recycle Back to MASX and the Required Fiber Length in the MADS

\begin{tabular}{lcc}
\hline Component & $\begin{array}{c}\text { Minimum Oil } \\
\text { Concentration } \\
(\mathrm{ppb})\end{array}$ & $\begin{array}{c}\text { Length of } \\
\text { Fiber Required } \\
(\mathrm{m})\end{array}$ \\
\hline Methylene Chloride & 47 & 28.9 \\
Trans-1,2-Dichloroethylene & 130 & 28.3 \\
Cis-1,2-Dichloroethylene & 120 & 28.7 \\
Chloroform & 91 & 30.2 \\
1,1,1-Trichloroethane & 340 & 28.4 \\
Carbon Tetrachloride & 770 & 23.8 \\
Benzene & 220 & 29.2 \\
Trichloroethylene & 340 & 27.2 \\
\hline
\end{tabular}

aSeries joining of modules. 
As shown in Table 9, chloroform controls the design of the MADS when the concentration of all components are equaldue to a combination of high required purity in the oil and its difficulty to strip from the oil. The component that controls the design must be evaluated on a case to case basis. It is determined by a combination of factors such as the purity required in the decontaminated water, its $D$-value in the extraction step, its oil-phase Henry's Law constant, and its oil phase diffusivity.

Since diffusion in the pores of the membrane dominates the mass transfer resistance in the MADS, this design calculation was largely based on a diffusivity estimate from the empirical form of the Stokes-Einstein Equation. Other forms to a.djust diffusivity have been proposed which give significantly different results from the Stokes-Einstein result. Compared to water, sunflower oil should have a much smaller diffusivity for each of the VOCs. It is also expected that diffusivity should increase with temperature. The trend in the Stokes-Einstein predicted result is in the right direction, but it is likely that it is not very accurate. Thus, the large size of the MADS required for this process may be an overly conservative design. Pilot studies are planned to verify the mass transfer in the MADS and obtain accurate measurements of local mass transfer coefficients.

\section{Condenser Performance Estimate}

The strip gas exiting the MADS will contain a trace of vaporized sunflower oil, but will contain mostly water vapor and VOCs. Water will be extracted into the sunflower oil in the MASX. Karl Fisher Titration results indicate that $1.98 \mathrm{~g} / \mathrm{L}$ sunflower oil will be extracted in the MASX at $20^{\circ} \mathrm{C}$. if all this water is assumed to vaporize in the MADS along with the VOCs, and this gas is passed through an equilibrium condenser at $10^{\circ} \mathrm{C}$, the condenser performance in Table 10 is expected. In this calculation, none of the sunflower oil is assumed to vaporize. Natural oils like sunflower oil, all triglycerides with $C_{18}$ fatty acid chain length, have very low vapor pressures $\left(1.3 \times 10^{-5}\right.$ atm at $254^{\circ} \mathrm{C}$ ) [SWERN-1979]. This low vapor pressure results in an insignificant amount of sunflower oil vaporization in the MADS. The Henry's Law constants published for water at $10^{\circ} \mathrm{C}$ were used in the condenser performance calculation. Some of the Henry's Law Constants for VOCs in water at $10^{\circ} \mathrm{C}$ were not published so they were estimated from data in the $20-25^{\circ} \mathrm{C}$ range [YAWS-1991, MUNZ-1987, 
KAVANAUGH-1980]. There is a large variation in published values of the Henry's Law constants for the VOCs in water, and these numbers will have to be verified experimentally.

As shown in the table, recovery of the VOCs from the strip gas is poor and this recovery is not high enough to recycle this gas back to the MADS. Although the concentration of VOCs in the product liquid is high, approaching $1 \%$ for each VOC, the flow rate of this water is small $\left(75 \mathrm{~cm}^{3} / \mathrm{min}\right)$ and most VOCs remain in the gas phase. In order to improve the performance of this condenser a lower temperature can be used. Another way to improve this design is to strye the condensers, but this improvement is not that significant, especially for components with large Henry's Law Constants in water such as carbon tetrachloride or 1,1/1-trichloroethane. In order to recycle the strip gas back to the MADS the gas must be cleaned much better. An adsorbent in the gas line would be required to recover enough VOCs to recycle the gas. Activated carbon could be used, but also it is possible to use sunflower oil at a low temperature $\left(20^{\circ} \mathrm{C}\right)$, with very small Henry's Law Constants, to recover the VOCs. The flow rate of this sunflower oil strip solution would be significantly lower than the flow in the MADS $(<0.01 \%)$. Experimental determination of this effect is currently planned. 
Table 10. Performance of MADS Condenser at $10^{\circ} \mathrm{C}$

\begin{tabular}{|c|c|c|c|c|c|}
\hline & $\begin{array}{c}\text { Inlet Flows } \\
\mathrm{moL} / \mathrm{min}\end{array}$ & $\begin{array}{c}\text { Henry's } \\
\text { constant } 10^{\circ} \mathrm{C} \\
\end{array}$ & $\begin{array}{l}\text { Exit Liquid } \\
\text { Conc. ppm } \\
\end{array}$ & $\begin{array}{l}\text { xit Vapor Flows } \\
\mathrm{moL} / \mathrm{min}\end{array}$ & $\begin{array}{l}\text { Percent Removal } \\
\text { from Strip Gas }\end{array}$ \\
\hline Strip Gas & 1.6777 & - & - & 1.6777 & - \\
\hline Water & 4.1607 & - & - & 0.0203 & 99.5 \\
\hline Methylene & 0.0446 & 0.040 & 10500 & 0.0353 & 20.7 \\
\hline \multicolumn{6}{|l|}{ Chloride } \\
\hline Trans-1,2- & 0.0390 & 0.133 & 11600 & 0.0301 & 22.9 \\
\hline \multicolumn{6}{|l|}{ Dichloroethylene } \\
\hline Cis-1,2- & 0.0390 & 0.147 & 11600 & 0.0301 & 22.9 \\
\hline \multicolumn{6}{|l|}{ Dichloroethylene } \\
\hline Chloroform & 0.0317 & 0.076 & 13600 & 0.0232 & 26.8 \\
\hline $1,1,1$ & 0.0284 & 0.352 & 14700 & 0.0201 & 29.1 \\
\hline \multicolumn{6}{|l|}{ Trichloroethane } \\
\hline Benzene & 0.0485 & 0.102 & 9800 & 0.0391 & 19.3 \\
\hline Carbon & 0.0246 & 0.606 & 16300 & 0.0167 & 32.1 \\
\hline \multicolumn{6}{|l|}{ Tetrachloride } \\
\hline Trichloroethylene & 0.0288 & 0.191 & 14600 & 0.0205 & 28.7 \\
\hline
\end{tabular}

\section{Conclusions}

Based on experimental equilibrium data for the sunflower oil-water-VOCs system and previous work evaluating mass transfer coefficients, the MASX/MADS concept is functional. High D-values significantly improve the MASX performance. The MADS performance is about the same for each VOC since all the diffusivities are about the same. The controlling feature in designing the MADS is the minimum oil concentration required for recycle, which depends on the D-value in the MASX. Thus, low D-value components, which require a high oil purity for recycle, or very low diffusivity components in the MADS, will determine the critical species in designing this device. Condenser performance after the MADS is calculated to be ineffective alone and only $20-30 \%$ of the VOCs are recovered from the gas phase in this condenser. Staging the condensers does not significantly improve its performance. In order to recycle the gas to the MADS, the VOCs must be removed by sunflower oil at 
$\sim 20^{\circ} \mathrm{C}$. Experimental pilot data (Water flow $40 \mathrm{~L} / \mathrm{min}$ ) is required to verify the mass transfer coefficients in both the MASX and especially the MADS to verify the design formulated here which was based on lab-scale experiments (Water flow $400 \mathrm{~cm}^{3} / \mathrm{min}$ ). Pilot mass transfer data to design the MADS is not yet available.

The design basis for the MASX/MADS requires a very high level of performance for this equipment, a decontamination factor of 1000 for the aqueous side. This factor is significantly larger than what is typical for competitive remediation equipment. If the system were operated at a larger O/A, the performance of the MASX would be improved. Also, the performance of the MADS would be improved due to the higher carry-over of water into the condenser. The design of the MASX/MADS will have to be optimize'd to determine its complete capabilities.

\section{Nomenclatu:e}

$a_{S}=$ Turbulent liquid surface area per unit bulk liquid volume, $\mathrm{cm}^{2} / \mathrm{cm}^{3}$

$a=$ Interfacial area per unit fiber volume, $\mathrm{cm}^{2} / \mathrm{cm}^{3}$

$\mathrm{C}_{\mathrm{oi}}=\mathrm{VOC}$ component $\mathrm{i}$ concentration in the oil phase, $\mathrm{mol} / \mathrm{cm}^{3}$ or $\mathrm{mg} / \mathrm{L}$

$C_{i}=$ VOC component $i$ concentration in the aqueous phase, $\mathrm{mol} / \mathrm{cm}^{3}$ or $\mathrm{mg} / \mathrm{L}$

$C_{o i}{ }^{*}=V O C$ component $i$ concentration in the oil phase that is in equilibrium with the $\mathrm{VOC}_{i}$ in the gas phase adjacent in the shell or at the turbulent liquid surface in the sparged gas reactor, $\mathrm{mol} / \mathrm{cm}^{3}$ or $\mathrm{mg} / \mathrm{L}$

$C_{i}^{*}=$ VOC component $i$ concentration in the aqueous phase that is in equilibrium with the $\mathrm{VOC}_{i}$ in the oil phase adjacent in the shell, $\mathrm{mol} / \mathrm{cm}^{3} \mathrm{or} \mathrm{mg} / \mathrm{L}$

$C_{i-i n}=$ Aqueous concentration of $\mathrm{VOC}_{i}$ entering the module, $\mathrm{mol} / \mathrm{cm}^{3}$ or $\mathrm{mg} / \mathrm{L}$

$\mathrm{C}_{\text {oi-in }}=$ Oil concentration of $\mathrm{VOC}_{i}$ entering the module, $\mathrm{mol} / \mathrm{cm}^{3}$ or $\mathrm{mg} / \mathrm{L}$

$\mathrm{C}_{\mathrm{gi}}=$ Gas concentration of $\mathrm{VOC}_{\mathrm{i}}$ entering the module, $\mathrm{mol} / \mathrm{cm}^{3}$

$D_{i}=D_{\text {-value }}$, organic concentration/aqueous concentration, dimensionless

$D_{A B}=$ Diffusivity of $\mathrm{VOC}_{i}, \mathrm{~cm}^{2} / \mathrm{s}$

$d_{I D}=$ Fiber ID, $\mathrm{cm}$ 
$d_{O D}=$ Fiber OD, $\mathrm{cm}$

$d_{\theta}=$ Fiber equivalent diameter, $\mathrm{cm}$

$d_{L M}=$ Fiber log-mean diameter, $\mathrm{cm}$

$\mathrm{G}=$ Gas rate, $\mathrm{moL} / \mathrm{s}$ or $\mathrm{cm}^{3} / \mathrm{s}$

$H_{i}=$ Dimensionless Henry's Law Constant for VOC $_{i}$

$\Delta \mathrm{H}_{\mathrm{i}, \text { diss }}=$ Enthalpy of dissolution of component $\mathrm{i}, \mathrm{J} / \mathrm{moL}$

$\Delta \mathrm{H}_{\text {vap }}=$ Enthalpy of vaporization of pure component $\mathrm{i} / \mathrm{J} / \mathrm{moL}$

$\mathrm{K}_{\mathrm{LS}}=$ Overall turbulent liquid mass transfer coefficient, $\mathrm{cm} / \mathrm{s}$

$K_{L}=$ Overall laminar liquid mass transfer coefficient, $\mathrm{cm} / \mathrm{s}$

$\mathrm{K}_{\mathrm{Lt}}=$ Tube-side mass transfer coefficient, $\mathrm{cm} / \mathrm{s}$.

$k_{m}=$ Membrane mass transfer coefficient, $\mathrm{cm} / \mathrm{s}$

$\mathrm{k}_{\mathrm{Ls}}=$ Shell-side mass transfer coefficient, $\mathrm{cm} / \mathrm{s}$

$\mathrm{R}=$ Universal gas constant, $\mathrm{cm}^{3} \cdot \mathrm{atm} / \mathrm{mol} \cdot \mathrm{K}$.

$R_{i}=V D_{i} / L$, dimensionless

$\Delta S_{i, \text { diss }}=$ Entropy of dissolution of $\mathrm{J} / \mathrm{moL}-\mathrm{K}$

$L=$ Aqueous flowrate in module, $\mathrm{cm}^{3} / \mathrm{s}$

$M_{w}=$ Molecular weight of water, $g / m o L$

$P=$ Pressure of the gas in the sparged reactor, atm

$\mathrm{t}=$ time, $\mathrm{s}$

$\mathrm{T}=$ Absolute temperature, $\mathrm{K}$

$v=$ Liquid velocity in fibers, $\mathrm{cm} / \mathrm{s}$

$V_{L}=$ Reactor liquid volume, $\mathrm{cm}^{3}$ 
$V_{i}=$ Molar volume of $\mathrm{VOC}_{i}$ solute, $\mathrm{cm}^{3} / \mathrm{moL}$

$\mathrm{V}=$ Oil flowrate in module, $\mathrm{cm}^{3} / \mathrm{s}$

$z$ = Fiber length, $\mathrm{cm}$

Greek Letters

$\varepsilon=$ Porosity of membrane, dimensionless

$\mu_{W}=$ Viscosity of water, $c p$

$\tau=$ Tortuosity of the membrane, dimensionless

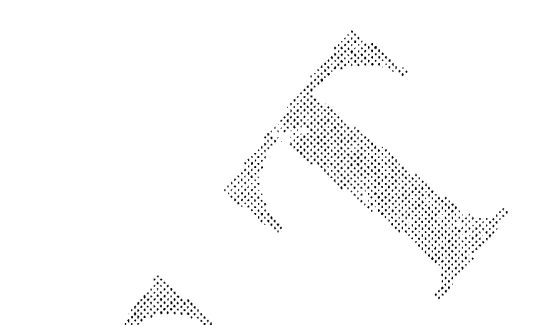




\section{References}

BIRD-1960

Bird, R. B., W. E. Stewart, and E. N. Lightfoot, Transport Phenomena, J. Wiley \& Sons, NY, 1960, 658-661.

BROWN and SULLIVAN-1991

Brown, R. A., and K. Sullivan, "Integrating Technologies Enhances

Remediation," Poll. Eng., 1991 23, 62-68.

HUTTER

Hutter, J. C. and G. F. Vandegrift, "Decontamination of Groundwater by Using Membrane Assisted Solvent Extraction," ACS Symp. Ser., No. 509, 47-60, 1992.

KAVANAUGH

Kavanaugh, M. C., and R. R. Trussel, Design of Aeration Towers to Strip Volatile Contaminants from Drinking Water, J. AWWA, Dec. 1980, 684-692.

KING-1982

King, C. J., et al., "Equilibrium Distribution Coefficients for Extraction of

Chlorinated Hydrocarbons and Aromatics from Water into Undecane," Env. Sci. Tech. 16(9) 624-627, 1982.

KING-1984

King, C. J., et al., "Solvnet Extraction for Removal of Polar Organic Pollutants from Water," Ind. Eng. Chem., Pro. Des. Dev. 23(4) 748-754, 1984.

LIDE

Lide, D. R., ed., CRC Handbook of Chemistry and Physics, 72 ed., CRC Press, Inc., Boca Raton Fl., 1991.

MACKAY-1979

Mackay, U., W. Y. Shiu, and R. P. Sutherland, "Determination of Air-Water Henry's Law Constants for Hydrophobic Pollutants," Env. Sci. Tech., 1979 13(3), 333-337.

METCALF \& EDDY

Metcalf \& Eddy, Inc., Wastewater Engineering: Treatment, Disposal, Reuse, McGraw-Hill Book Co.. Inc. 1979.

MCWHIRTER

McWhirter, J. R., ed., The Use of High Purity Oxygen in the Activated Sludge Process, CRC Press, Boca Raton FL, 1978.

MCWHIRTER and HUTTER, 1989

McWhirter, J. R., and J. C. Hutter, "Improved Oxygen Mass Transfer Modeling for Diffused/Subsurface Aeration Systems," AlChE J., 1989 35(9), 1527-1534. 
MUNZ

Munz, C., and P. V. Roberts, "Air-Water Phase Equilibria of Volatile Organic Solutes," J. AWWA, May 1987, 62-69.

OKONIEWSKI

Okoniewski, B. A., "Remove VOCs from Wastewater by Air Stripping,", CEP, Feb. 1992, 89-93.

PERRY

Perry, R. H., ed., Perry's Chemical Engineer's Handbook, 6 th ed., McGraw-Hill Book Co., 1984.

PRASAD AND SIRKAR-1987

Prasad, R., and K. K. Sirkar, "Solvent Extraction with Microporous Hydrophilic and Composite Membranes," A/ChE J., 1987 33(7), 1057-1066.

PRASAD and SIRKAR-1988

Prasad, R., and K. K. Sirkar, "Dispersion-Free Solvent Extraction with

Microporous Hollow-Fiber Modules," A/ChE J., 1988 34(2), 177-188.

PRASAD and SIRKAR-1990

Prasad, R., and K. K. Sirkar, "Hollow Fiber Solvent Extraction: Performances and Design," J. Mem. Sci., 1990 50, 153-175.

ROBERTS

Roberts, P. V., C. Munz, and P. Dandliker, "Modeling Volatile Organic Solute

Removal by Surface and Bubble Aeration," J. WPCF, 56(2), 1984.

SEMMENS

Semmens, M. J., "Method of Removing Organic Volatile and Semivolatile

Contaminants from Water," U. S. Patent No. 4960520, 1990.

SMITH and BOMBERGER-1978

Smith, J. H., D. C. Bomberger, "Prediction of Volatitization of Chemicals in

Water", AlChE Sym. Ser., 75(190), 1978, 375-381.

SWERN

Swern, D., ed., Bailey's Industrial Oil and Fat Products, 4th ed., John Wiley \& Sons, Inc., 1979.

WISE and HOUGHTON

Wise, D. L., and G. Houghton, "The Diffusion Coefficients of 10 Slightly Soluble

Gases in Water at 10-60 C," Chem. Eng. Sci., 21, 1966, 999.

YANG and CUSSLER-1986

Yang, M.-C., and E. L. Cussler, "Designing Hollow-Fiber Contactors," AlChE J., 1986 32(11), 1910-1916. 
YAWS

Yaws, C., H. C. Yang, and X. Pan, "Henry's Law Constants for 362 Compounds in Water," Chem. Eng., Nov. 1991, 179-185.

\section{ZANDER-1989A}

Zander, A. K., R. Qin, and M. J. Semmens, "Membrane/Oil Stripping of VOCs from Water in a Hollow Fiber Contactor," J. Env. Eng., 1989 115, 768-784.

ZANDER-1989B

Zander, A. K., M. J. Semmens, and R. M. Narbaitz, "Removing VOCs by Membrane Stripping," J. AWWA, Nov. 1989, 76-80. 


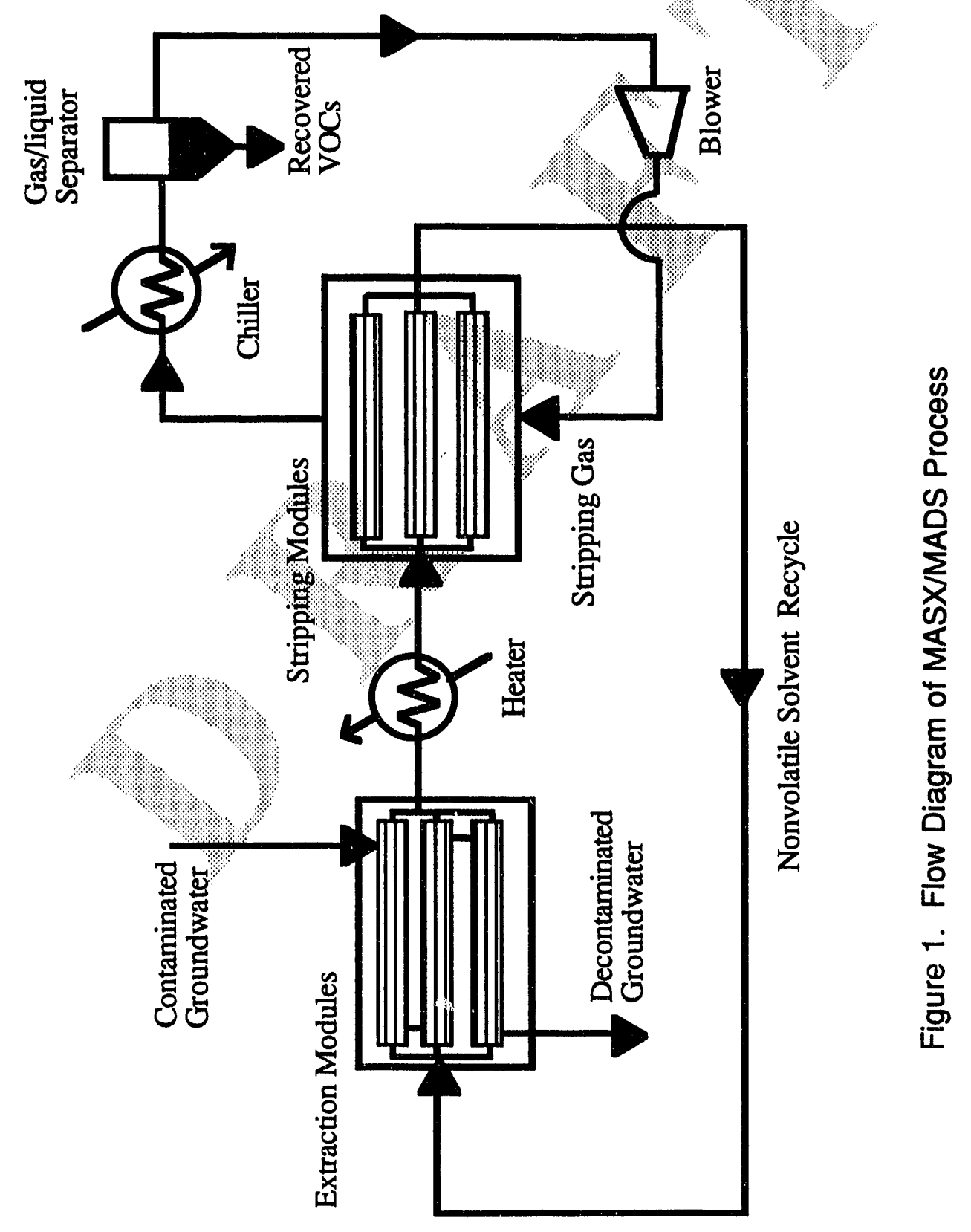




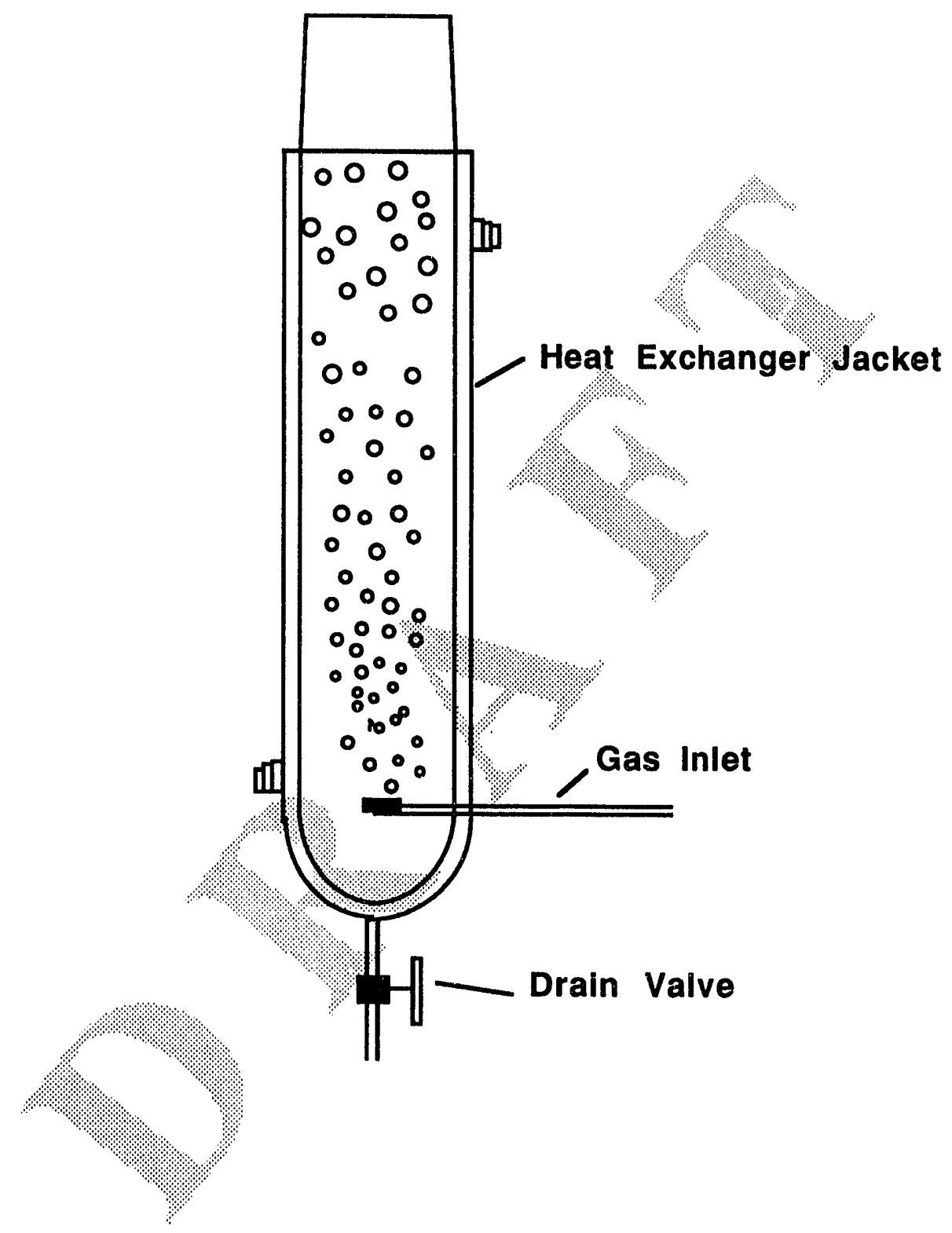

Figure 2. Sparged Reactor Used to Evaluate Henry's Law Constants of VOCs in Sunflower Oil 


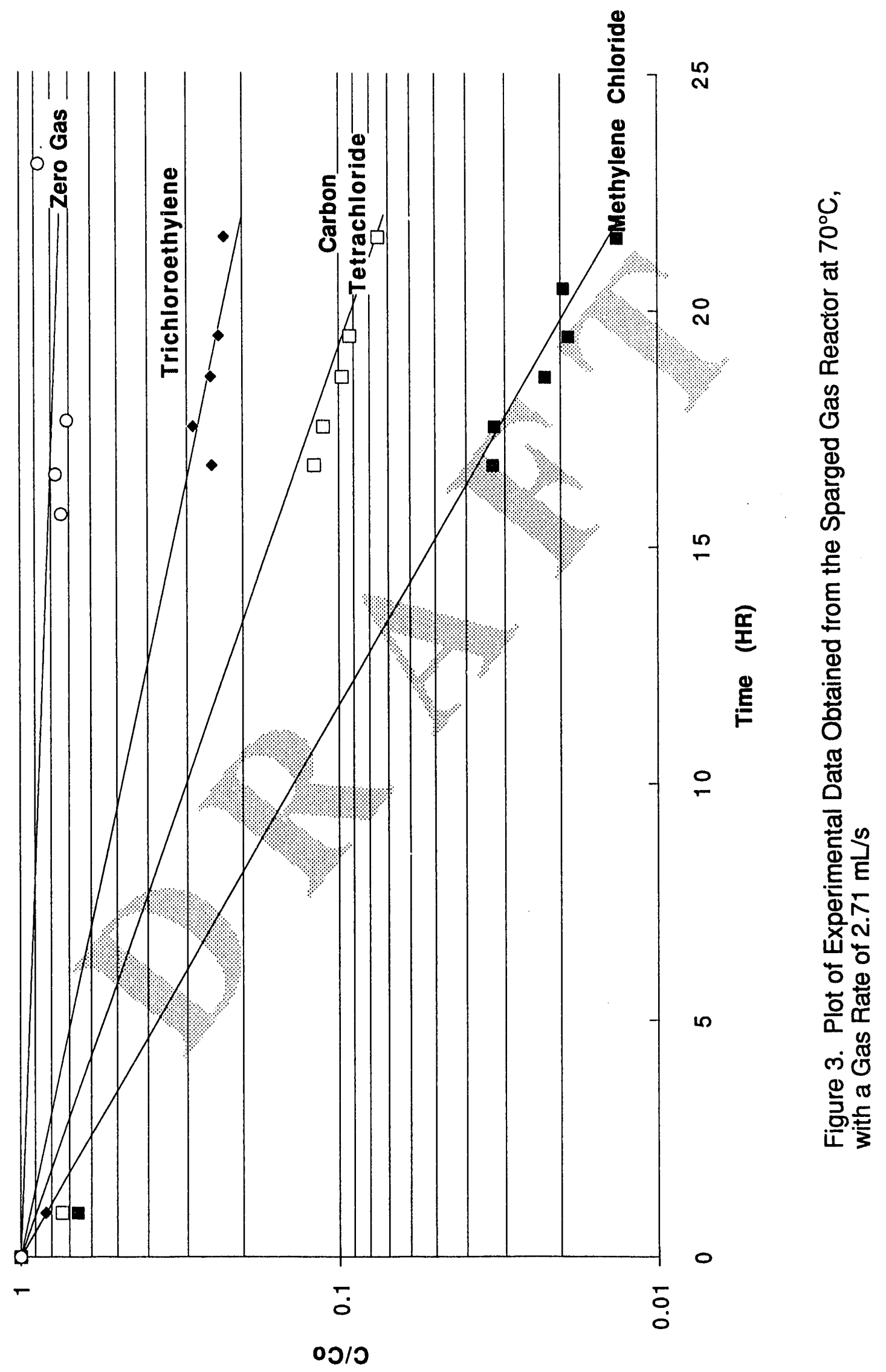




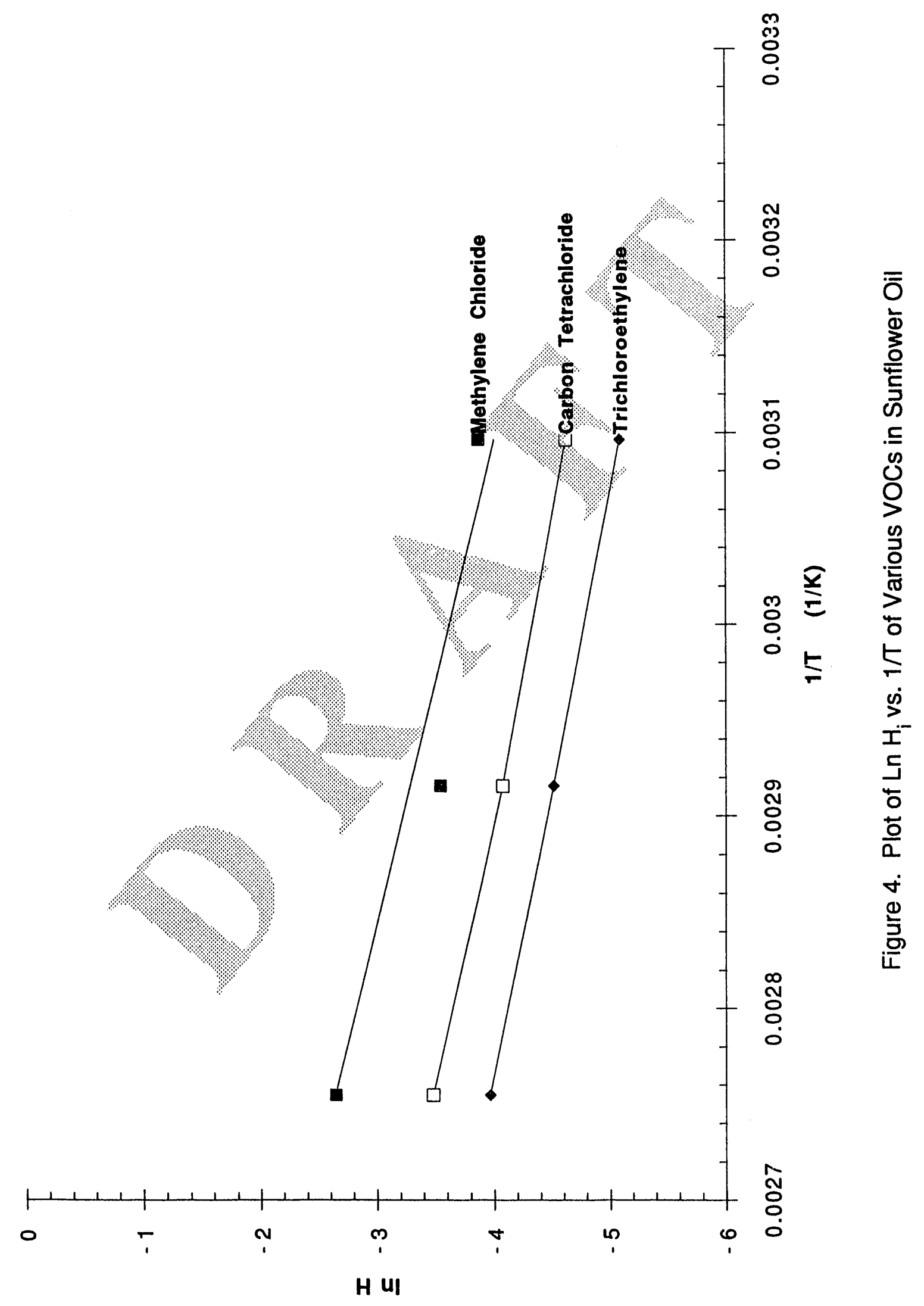




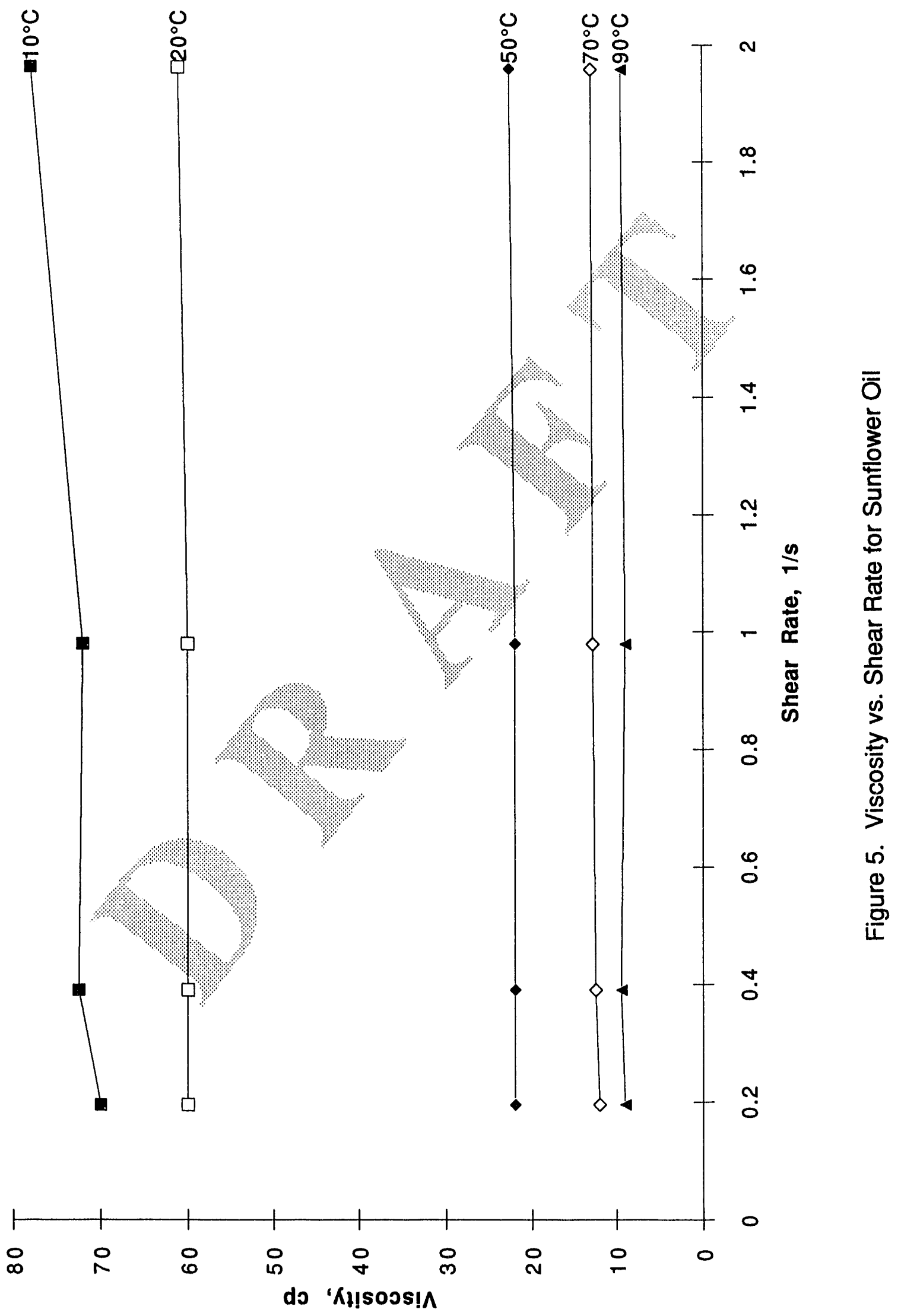




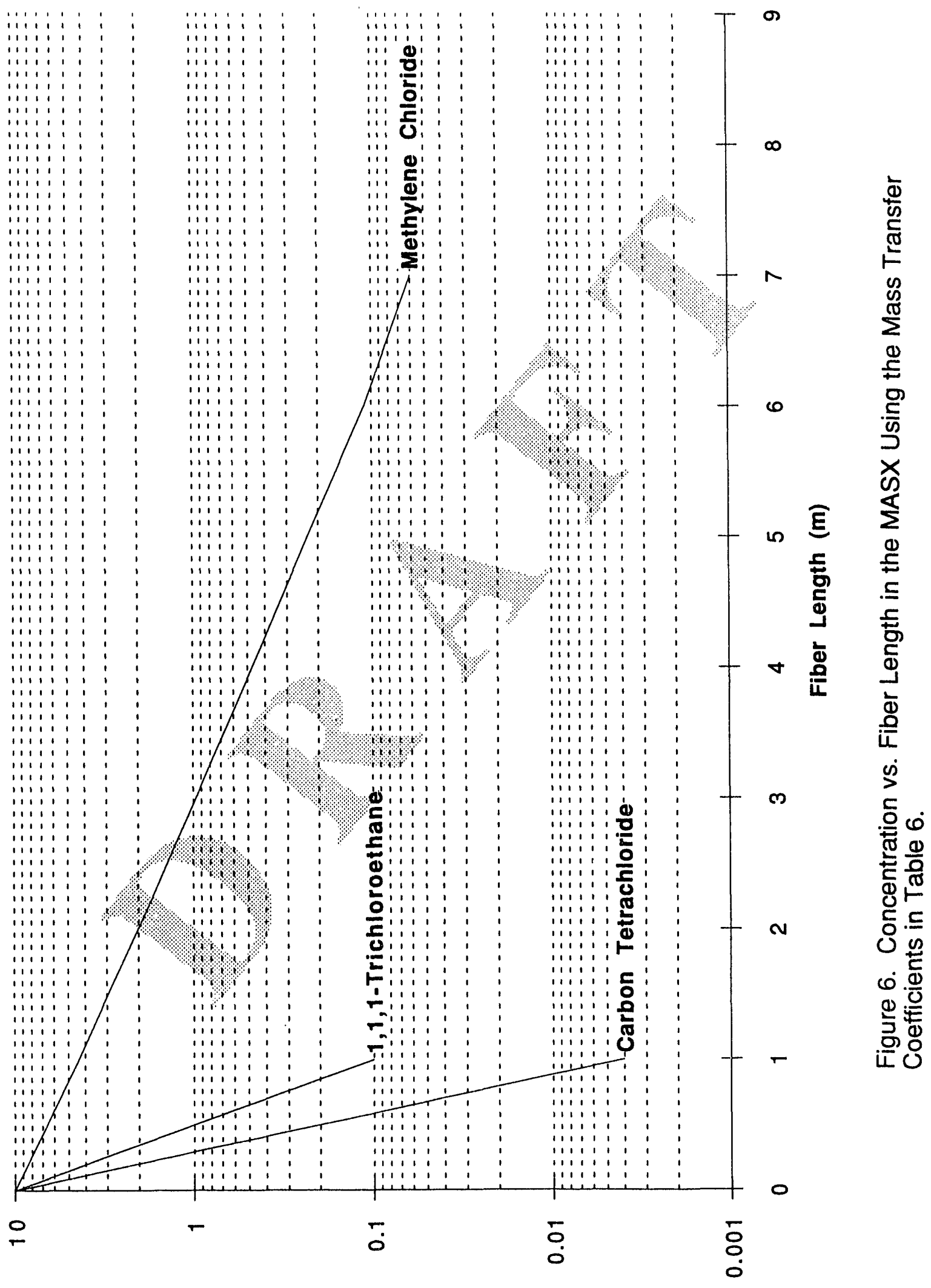

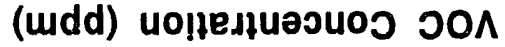




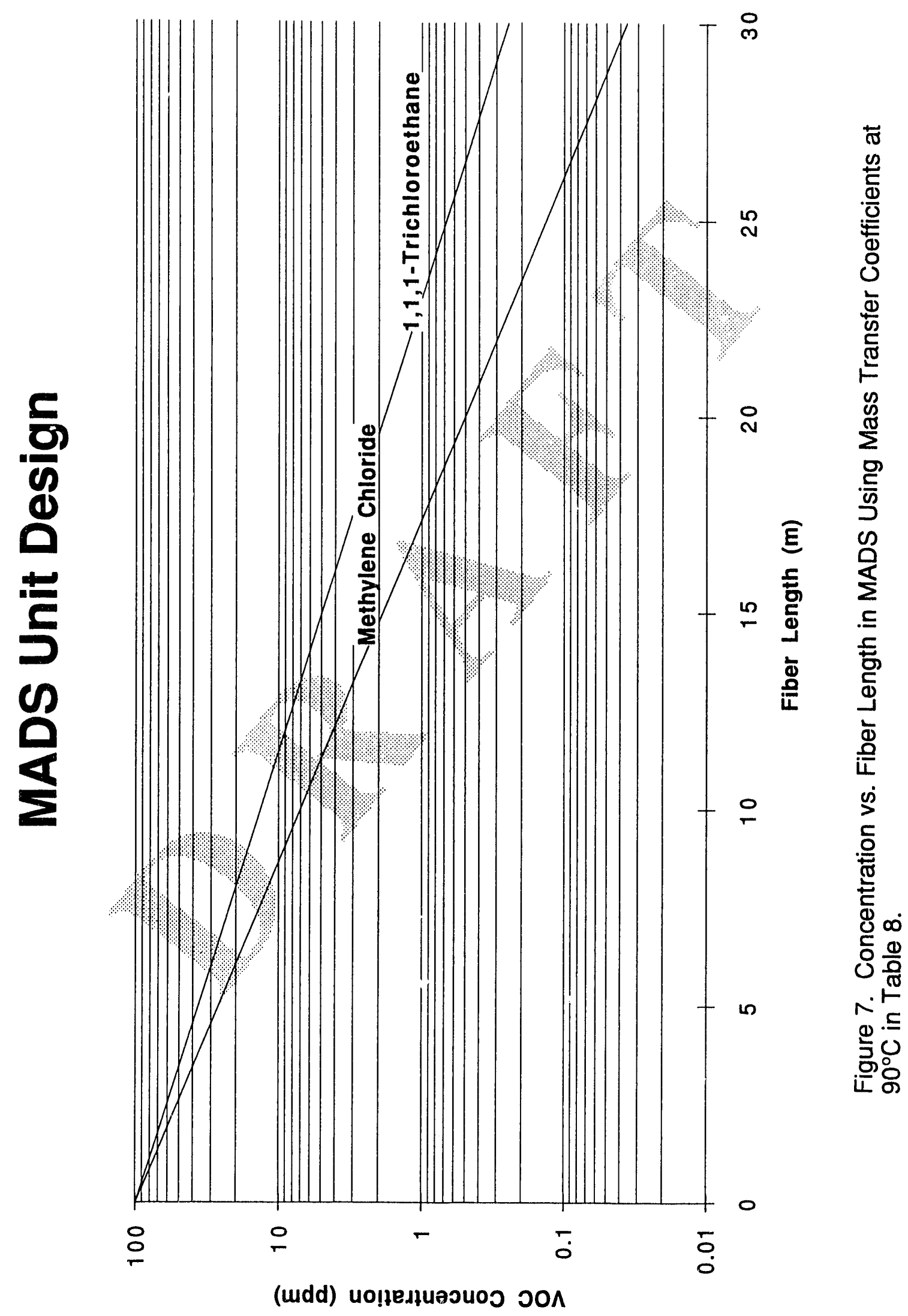



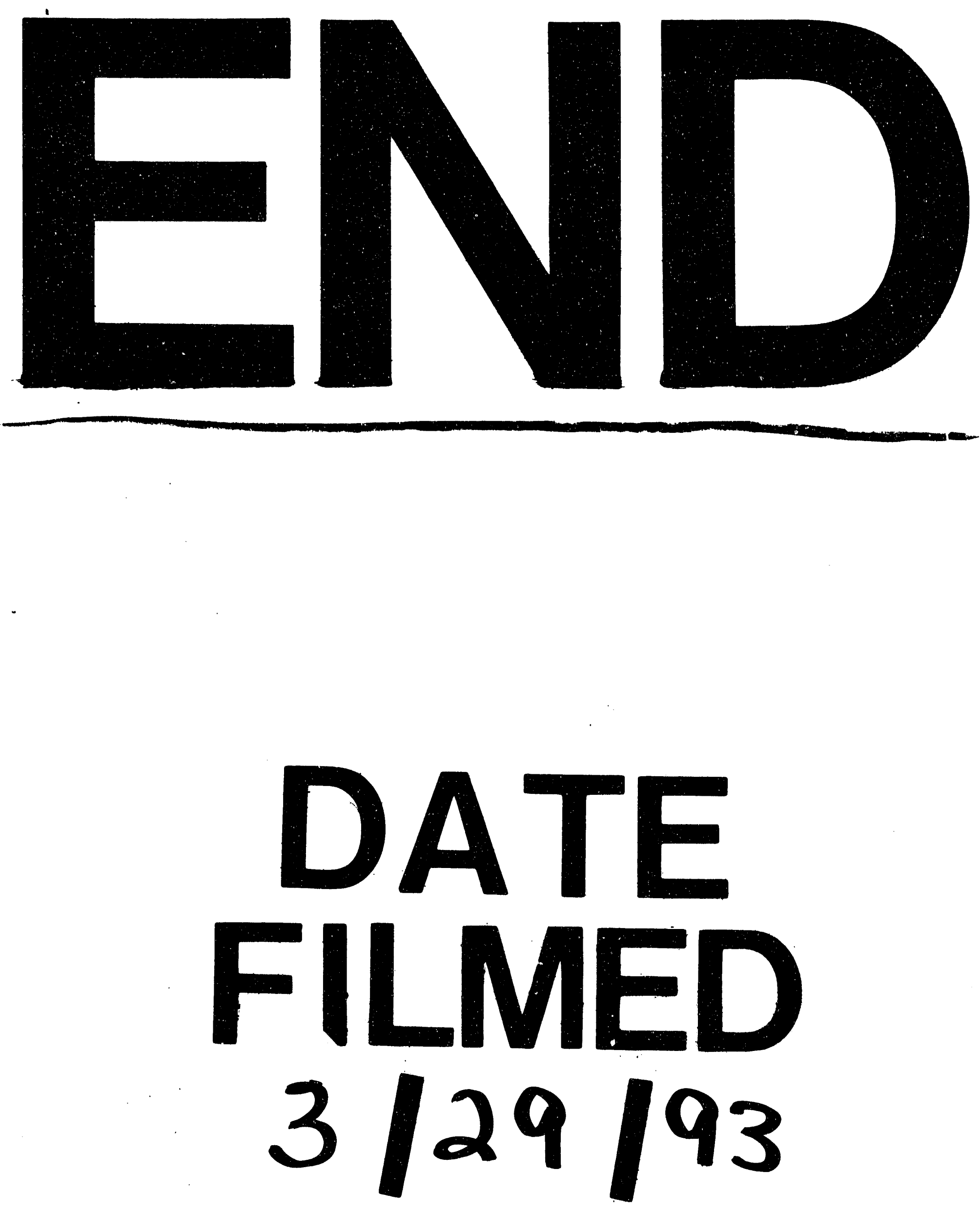


\section{"}

